\title{
Participant incentives in rehabilitation research: a pilot study of researchers' perspectives
}

\author{
Pragashnie Govender, Deshini Naidoo, Urisha Naidoo
}

University of KwaZulu Natal (Westville campus)-School of Health Sciences, Private Bag x54001 Durban 4000, Westville, KwaZulu-Natal 4052, South Africa.

\begin{abstract}
Background: Despite the use of research incentives in the recruitment and retention of participants for research studies, there remains debate over the acceptable use of participant incentives in research. There appears to be a paucity of guidelines that can assist researchers in demonstrating practically how incentives may be ethically used in research.

Objective: This single site pilot study explored the experiences of key stakeholders involved in rehabilitation research to highlight what may constitute acceptable practices for incentives.

Methods: A qualitative inquiry with use of semi-structured interviews with four key informants from a single site was undertaken. Data was audio-recorded and analysed thematically using deductive reasoning.

Results: The findings reflect a description of what incentives constitute; the issues around undue inducement and use of incentives in practice. Participants' offered their perceptions on perceived acceptable versus unacceptable practices in the use incentives in research. Participants shared their concern over research incentives being used to sway participation in research rather than reimburse participants for their expenses or offering a token of appreciation.

Conclusion: There is a need for education of practitioners and researchers to develop skill to aid researchers to evaluate the ethical dilemmas related to the use of incentives in research.

Keywords: Participant incentives, rehabilitation research, researchers' perspectives.

DOI: https://dx.doi.org/10.4314/ahs.v19i3.54

Cite as: Govender P, Naidoo D, Naidoo U. Participant incentives in rehabilitation research: a pilot study of researchers' perspectives. Afri Health Sci. 2019;19(3): 2778-2783. https:// dx.doi.org/10.4314/abs.v19i3.54
\end{abstract}

\section{Background}

Historically, there have been research discoveries that were made at the expense of vulnerable populations. These well documented studies included investigations such as the Tuskegee Syphilis Study and Woolbrook study ${ }^{1-3}$. These studies highlighted significant ethical breaches in autonomy of research participants, which promulgated the drafting and adoption of policies to establish and regulate human subject's protection. Some of these policies include the Nuremberg Code ${ }^{4}$, the Belmont Report ${ }^{5,6}$ and

\section{Corresponding author:}

Pragashnie Govender, University of KwaZulu Natal (Westville campus)-School of Health Sciences, Private Bag x54001 Durban 4000, Westville, KwaZulu-Natal 4052, South Africa.

Email: naidoopg@ukzn.ac.za the Declaration of Helsinki World Medical Association, 1964.

The research landscape is continually evolving with pressure on researchers to ethically recruit and retain participants in research studies. In doing so, researchers often look to providing incentives for participants especially in studies that require samples that are difficult to access or those requiring extended periods of time for completion. Only three acceptable forms of recruitment have been described in the literature, namely voluntary participation, wages or incentives ${ }^{8,9}$. Four models of reimbursement exist, namely, the market model, where payment is based on supply and demand and includes completion bonuses; wage payment model which is based on standardised wage for time and effort commensurate with wages for unskilled essential jobs, reimbursement model which includes expenses incurred, travel, meals, accommodation and appreciation model which includes a token of appreciation given at the end of a study ${ }^{10,11}$. However, recruitment and payment of incentives to research participants poses predicaments for both researchers and insti-

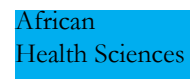

2778
(C) 2019 Govender et al. Licensee African Health Sciences. This is an Open Access article distributed under the terms of the Creative commons Attribution License (https://creativecommons.org/licenses/BY/4.0), which permits unrestricted use, distribution, and reproduction in any medium, provided the original work is properly cited. 
tutional review boards (IRBs). There may be instances in which the use of incentives to recruit and retain research subjects or participants is entirely innocuous, however there are some areas or instances in which this is not the case. Some examples cited from the literature that include breaches of ethical code include the following; A psychology professor providing students with extra credit when agreeing to participate in a research study ${ }^{8}$, parents may be enticed to provide consent for their child's participation based on the offer of payment which can unwittingly distort their decision making against the risk factors of their child's participation ${ }^{12}$, and a prisoner whose care and treatment may be compromised for refusal of participation in a study ${ }^{11}$.

A central tenet of informed consent is the requirement that participation must be voluntary and free from coer$\operatorname{cion}^{5,7}$. However, autonomy has been documented as one of the most often compromised ethical principles in research involving human subjects ${ }^{13}$ especially in situations where the participant's decision is unduly influenced or coerced by an incentive. These issues around incentives are currently debated, including the definition, what constitutes a breach of ethical code, what may constitute ethical incentives and how IRBs view and make decisions about these issues ${ }^{8,14-16}$.

The Belmont Report, explains that, "Coercion occurs when an overt threat of harm is intentionally presented by one person to another in order to obtain compliance" by contrast, undue influence "occurs through an offer of excessive, unwanted, inappropriate or improper reward or other overture in order to obtain compliance" $" 5,6$. An excessively attractive offer that leads people to exercise poor judgment about research participation that involves a risk of serious harm ${ }^{17}$.

In the rehabilitation field, researchers are urged to consider participants from vulnerable populations. In our diverse context these may, include, but are not limited to, children, women, participants who are institutionalised e.g. prisoners and physically and mentally impaired individuals ${ }^{18}$. It is essential for researchers to consider ethical use of incentives with these particular populations. How- ever, there are currently no explicit guidelines for how incentives may be used; except for guidelines provided for clinical trials. The authors therefore harboured concerns over what constitutes ethical versus unethical use of incentives, which may compromise valid informed consent and sample bias and hence aimed to explore this in a pilot study. Without implicit guidelines, research integrity and participants rights may be infringed; and an understanding on what may be acceptable and non-acceptable practices for incentives especially for research within the rehabilitation context is required.

\section{Methods}

This study sought to explore the experiences of key rehabilitation research stakeholders in a single site study toward improving the understanding of what constitutes ethico-legal practices in research with incentives. The authors undertook an explorative qualitative inquiry ${ }^{19}$ with the use of semi-structured interviews. The study was located within the College of Health Sciences at the University of KwaZulu-Natal. Via purposive sampling, four key informant participants were recruited based on specific selection criteria. The participants were required to have at least five years of research experience, and have participated in research within the health science context. Demographic information was retrieved via a biographical questionnaire. Data were analysed deductively using content analysis. Coding was initiated prior to categories and merging of themes towards drawing and verification of conclusions ${ }^{20}$. The authors were aware of their position within the research process and occupied a hybrid stance that is, between the insider and outsider perspective as all authors were involved in research but with limited experiences in research projects involving incentives ${ }^{21}$. In order to ensure trustworthiness, the authors ensured investigator triangulation in data analysis ${ }^{22}$ by each individually analysing the transcripts prior to discussions towards consensus; by the use verbatim quotes to describe the data as well as attempts at being reflexive within the research process. Ethical principles of beneficence (doing good) by contributing to good practice in research, veracity by ensuring accurate reporting and use of verbatim 
quotes, confidentiality de-identification of participants and scientific honesty and integrity were maintained in this study ${ }^{7}$.

\section{Findings}

All four participants were in receipt of a doctoral degree and had a level of experience in research from between seven to 20 years. All participants were reviewers of research proposals in the rehabilitation professions. All participants had used incentives in research.

The authors reduced the data to reflect three emergent themes namely, a description of what incentives constituted; undue inducement and incentives in practice.

\section{Theme one: What are incentives?}

The participants agreed on what constituted an incentive. Examples provided included the use of financial incentives, reimbursement for transport and the participants' time, offering refreshments and provision of services to those who may be identified in the study as requiring intervention. The participants agreed that the principal researcher needs to cover the basic costs incurred by the participants in the research study. These issues are illustrated by the quotes below:

"I think a monetary value, putting a monetary value on it saying I would pay you X amount for each session, I think that's a nono. But I think on the humanitarian side for instance, food and transport costs that you pay directly for taxi, if they can bring you a receipt that this is what the taxi costs, or you know how much the taxi costs for you to get there, I think that is totally acceptable"

"I don't think presents ... should be allowed. But and that's why I focused on transport and refreshments because I think that is quite acceptable in my opinion. But no presents or money"

"I think at all times the researcher needs to make sure that whatever cost the participant has to bear, whether it is a transport cost...... providing food or refreshment or reimbursing them for anything that they bave to pay out of their pocket. It's at the minimum that one should do"

"Incentives can and should include things like recognition, social support"

\section{Theme two: Undue inducement}

The participants reported that incentives could possibly sway participants in research studies and influence them to participate even when the study is high risk. In the rehabilitation field, this may refer to new techniques, devices etc. that could potentially cause harm. Additionally, undue inducement can reduce research participant's ability to make informed decisions especially when the incentives potentially blind their understanding to risks and in making informed decisions. Financial incentives could potentially make participants in a study dependent on the income generated thus unduly motivated them to participate in a study despite the risks incurred.

"You can explain the risks and benefits to someone but they may be so desperate that the money seems far more attractive than mild damage to your kidneys or a dry mouth or withdrawal [effects] of the drug post initiation"

"Especially in a place like South Africa where you have a large population of people who are not research wise, people don't know what's happening enough that the money seems to be more of the carrot'

"I think incentives go in conflict with certain research methodologies... in rural based research and community based research it flies in the face of who[researcher/participant] initiates and why they [researcher/participant] initiate and the trust and faith factor. So it's not about the goodwill contract...people [participants] do it because they do it for the money"

"I think ethically one has to be very careful that there isn't a significant advantage to the participant. That there's nothing that is going to persuade them to participateagainst their will or better judgement or sway their decision"

\section{Theme three: Incentives in practice}

Participants reported incentives to have several advantages. These include facilitating easy recruitment and helping in maintaining a sample size.

"Helps maintain the sample size"

However, practical challenges in the use of incentives were noted. Examples provided, included dependency especially with pharmaceutical incentives and the need for services to be provided beyond the study post trial access and; psychosocial support beyond scope of study. Examples from rehabilitation included good practice including offering of intervention following participation in a study 
if the participant was identified as requiring intervention, assisting to set up rehabilitation services in the study location, if a number of participants were identified as requiring intervention and as part of the advocacy role of rehabilitation researchers. Being transparent about the length of time that the incentives will be offered, as expectations may be set by the participants who become recipients of the intervention.

It's on a knife's edge what you can give and what you can't do-I don't want to use payback... but it's payback to the people that participated in your research to actually say thank you that they are part of your sample size and they assist you in the research... it's an incentive... there is a fine line between... swaying the person towards your findings or giving them something just to do your research"

"There is a very line between thanking someone for their participation and buying their participation. But to the participants they are inappropriately swayed into participation because it's an income. It's an income for a month or it's an income for the next few weeks. Ja, ja... that's immoral as far as I'm concerned and that there isn't enough control. It's up to every researcher and presumably every research body... Researchers are going through the appropriate processes that are there to protect the participant. But I know that there are many cases where this does not happen where the researchers don't go through the process that's required"

"Especially our situation where were are [rehabilitation] service providers, I think the line is more blurred there, because we provide a service and our clients wants a service, they want a good service, not that our service is affected, it would be provided whether you participate or not participated in the study. Some of the popular participants are so grateful that you include them in your study because they know they will get maybe extra training, they will money to get there and food, that kind of thing, so it does help them. But the negative thing is they are so grateful that you do these things for them that they will say anything that will register positive towards your results, do you understand what I mean"

\section{Discussion}

The findings suggest that there is no clear explanation for how researchers perceive acceptable versus unacceptable incentives.

Generally, the findings reflect that incentives have several advantages, namely, i) facilitates easy recruitment ii) helps maintain sample size and, iii) gets the research going within a reasonable time frame. Additionally, Grady ${ }^{11}$ indicates the value of incentives in also ensuring that par- ticipants incur no costs are revenue-neutral experiences, and can be a sign of respect for participation. There appeared to be consensus on aspects such as participants being paid for their time, inconvenience, and travel and receiving refreshments as a courtesy. This is consistent with the reimbursement model and appreciation models described in the literature $\mathrm{i}^{10,11}$.

On the other hand incentives were seen to possibly sway participation in research. Practical challenges in the use of incentives in research include i) judgement of when use of incentives reduces participant autonomy ii) coercion of participants iii) undue influence of participants and iv) extension and continuation of services outside of the study. Concerns over the South African context arose, in that the promise of money could lead participants towards exercising poor judgement about research participation despite the potential risks that may be involved. There exists a significant body of literature on undue inducement ${ }^{14,17,22,23}$. In a study by Klitzman ${ }^{14}$ of 34 IRBs in the USA, ambiguities and lack of consistent standards emerged. IRBs wrestled with defining the terms 'coercion' and 'undue inducement', and were unsure around decisions about participant compensation. These terms appeared to be used synonymously and hence tensions arose around whether subjects should get paid versus volunteer that is, whether subjects should be motivated by compensation versus altruism, and whether subjects should be paid differently based on income, given possible resultant selection bias. London and colleagues ${ }^{24}$ also suggest that use of financial incentives for recruitment and retention are controversial as has the potential to negatively impact on the autonomy of participants. However, the possibility of "undue inducement" can be reduced by ensuring that incentives not be so large or extensive so as to induce prospective subjects to consent to participation in the research against their better judgement ${ }^{25}$ and the risks associated with the study be addressed carefully in informed consent documentation to assist participants making an informed decision ${ }^{26}$. Additionally, the mandate of IRBs as gatekeepers, should be to ensure that the risk to participants are reasonable against the potential risk-ratio benefit to assist researchers in ensuring ethical research practice.

\section{Conclusion}

This study has contributed to the debate around use of 
incentives in research. Given that there remains ambiguity in what constitutes acceptable versus unacceptable practice, researchers are encouraged to consider the motives behind offering an incentive to participants. Researchers are to practice judgement in their use of incentives and be aware of how this may influence the autonomy of participants and in ensuring that coercion and undue influence are reduced in all stages of the research process; from recruitment to completion. Monitoring and auditing of incentives in research are essential, within which IRBs can serve as gatekeepers in protecting research participants. In the absence of explicit guidelines, sensitisation and development of expertise to evaluate ethical dilemmas related to incentives are required. Further research is required into determining how incentives are used in rehabilitation across a wider context as well as to determine guidelines that are used by IRBs in making decisions around acceptable use of incentives.

\section{Conflict of interest}

None to declare.

\section{Acknowledgement}

The authors would like to acknowledge Dr. Blessing Silaigwana, who contributed towards the conceptualisation and data collection phases of the study.

\section{References}

1.Fairchild AL, Bayer R. Uses and abuses of Tuskegee. Science. 1999 May 7;2845416:919-21.

2. Rothman DJ. Were Tuskegee \& Willowbrook 'studies in nature'?. Hastings Center Report. 1982 Apr;122:5-7.

3. Krugman S. The Willowbrook hepatitis studies revisited: ethical aspects. Reviews of Infectious Diseases. 1986 Jan 1;81:157-62.

4. The Nuremberg Code. Trials of war criminals before the Nuremberg military tribunals under Control Council Law. 1949;10:181-2.

5. Department of Health E. The Belmont Report. Ethical principles and guidelines for the protection of human subjects of research. The Journal of the American College of Dentists. 2014;813:4.

6. Department of Health E. The Belmont Report. Ethical principles and guidelines for the protection of human subjects of research. The Journal of the American College of Dentists. 2014;813:4.
7. World Medical Association. World Medical Association Declaration of Helsinki. Ethical principles for medical research involving human subjects. Bulletin of the World Health Organization. 2001;794:373.

8. Grant RW, Sugarman J. Ethics in human subjects research: do incentives matter?. Journal of Medicine and Philosophy. 2004 Dec 1;296:717-38.

9. Frederick M. Offering incentives for research participation. WSIRB In-Service Training. DSHS Human Research Review Section. 2009:1-4.

10. Dickert N, Grady C. What's the price of a research subject? Approaches to payment for research participation.

11. Grady C. Payment of clinical research subjects. The Journal of Clinical Investigation. 2005 Jul 1;1157:1681-7.

12. Wendler D, Rackoff JE, Emanuel EJ, Grady C. The ethics of paying for children's participation in research. The Journal of Pediatrics. 2002 Aug 1;1412:166-71.

13. Berg JW, Appelbaum PS, Lidz CW, Parker LS. Informed consent: legal theory and clinical practice. Oxford University Press; 2001 Jul 12.

14. Klitzman R. How IRBs view and make decisions about coercion and undue influence. Journal of Medical Ethics. 2013 Apr 1;394:224-9.

15. Hanson RK, Letourneau EJ, Olver ME, Wilson RJ, Miner MH. Incentives for offender research participation are both ethical and practical. Criminal Justice and Behavior. 2012 Nov;3911:1391-404.

16. Dugosh KL, Festinger DS, Croft JR, Marlowe DB. Measuring coercion to participate in research within a doubly vulnerable population: Initial development of the coercion assessment scale. Journal of Empirical Research on Human Research Ethics. 2010 Mar;51:93-102.

17. Emanuel EJ, Wendler D, Killen J, Grady C. What makes clinical research in developing countries ethical? The benchmarks of ethical research. The Journal of Infectious Diseases. 2004 Mar 1;1895:930-7.

18. National Bioethics Advisory Commission. Ethical and policy issues in research involving human participants. 2001.

19. Creswell JW, Creswell JD. Research design: Qualitative, quantitative, and mixed methods approaches. Sage Publications; 2017 Dec 12.

20. Braun V, Clarke V, Hayfield N, Terry G. Thematic analysis. Handbook of Research Methods in Health Social Sciences. 2019:843-60. 
21. Jootun D, McGhee G, Marland GR. Reflexivity: promoting rigour in qualitative research. Nursing standard. 2009 Feb 11;2323:42-7.

22. Martin R. Undue inducement in clinical research. The Lancet. 2005 Jul 23;3669482:275-6.

23. Wilkinson M, Moore A. Inducement in research. Bioethics. 1997 Oct;115:373-89.

24. London AJ, Borasky Jr DA, Bhan A, Ethics Working Group of the HIV Prevention Trials Network. Improving ethical review of research involving incentives for health promotion. PLoS medicine. 2012 Mar 27;93:e1001193.

25. Greenwald AS, Bassano A, Wiggins S, Froimson MI. Alternative reimbursement models: bundled payment and beyond: AOA critical issues. JBJS. 2016 Jun 1;9811:e45. 26. Council for International Organizations of Medical Sciences. International ethical guidelines for biomedical research involving human subjects. Bulletin of medical etbics. 2002 Oct182:17. 